\title{
Building information modelling to support maintenance management of healthcare built assets
}

*Nadeeshani Wanigarathna

Department of Engineering and the Built Environment, Anglia Ruskin University, City, UK

Bishop Hall Lane, Chelmsford CM1 1SQ.

Nadeeshani.wanigarathna@anglia.ac.uk

Telephone: 00447413333269

\section{Keith Jones}

Department of Engineering and the Built Environment, Anglia Ruskin University, City, UK

Bishop Hall Lane, Chelmsford CM1 1SQ.

\section{Adrian Bell}

Department of Engineering and the Built Environment, Anglia Ruskin University, City, UK

Bishop Hall Lane, Chelmsford CM1 1SQ.

Georgios Kapogiannis

Digital City Infrastructure and Technology Innovation Laboratory (D-CiTi Lab), The University of Nottingham

199 Taikang East Road, Ningbo, 315100, China

\section{Acknowledgement}

The work was funded by Royal Institution of Chartered Surveyors. The authors also wish to acknowledge the Princess Alexandra hospital who participated in the case study.

* Corresponding author 


\title{
Building information modelling to support maintenance management of healthcare built assets
}

\author{
Abstract
}

- Purpose: This research investigated how digital capabilities associated with Building Information Modelling can integrate a wide range of information to improve built asset management decision making during the in-use phase of hospital buildings.

- Research methodology: A comprehensive document analysis and a participatory case study was undertaken with a regional NHS hospital to: review the type of information that can be used to better inform BAM decision making; to develop a conceptual framework to improve information use during the healthcare built asset management process; to test how the conceptual framework can be applied within a BAM division of a healthcare organisation; and to develop a cloud-based BIM application.

- Findings: BIM has the potential to facilitate better informed built asset management decision making by integrating: a wide range of information related to the physical condition of built assets; resources available for built asset management; and the built asset's contribution to healthcare provision within an organisation. However, interdepartmental information sharing requires: a significant level of time and cost investment; and changes to information gathering and storing practices within the whole organisation.

- Originality/value: This research demonstrated that the implementation of BIM during the in-use phase of hospital buildings is different to that in the design and construction phases. At the in-use phase BIM needs to integrate and communicate information within and between the estates, facilities division and other departments of the organisation. This poses a significant change management task for the organisation's information management systems. Thus, a strategically driven top-down organisational approach is needed to implement BIM for the in-use phase of hospital buildings.

Keywords: Building Information Modelling, Healthcare, Built asset Management, Information integration, Organisational Performance, Built Asset Maintenance

\section{Introduction}

The way we look at our buildings and other physical assets, such as plant and equipment, has changed gradually. Built asset management professionals and scholars increasingly recognise that built assets should add value to the core business of the organisation, which goes beyond just maintaining a building's physical condition (Støre-Valen and Lohne, 2015). For example, RICS (2008) defines public sector built asset management as 'a structured process that seeks to ensure best value for money from property assets in serving the strategic needs of public sector organisations'. Within the context of healthcare buildings, Støre-Valen and Lohne (2016) define value as the hospital buildings ability to create optimal conditions for effective delivery of healthcare services. Conveying a similar approach, RICS emphasises that public sector Built Asset Management (BAM) should entail a strategically driven process to ensure that the optimisation of an organisation's assets supports its key business goals and objectives (RICS, 2012). Similarly, organisations increasingly recognise buildings as a critical asset to fulfil organisational strategic objectives, and not just as envelopes providing shelters for people and activities (Steinke et al., 2010). BAM should entail strategically 
driven processes throughout the whole building life-cycle: planning and acquisition, maintenance, and disposal or replacement. Asset planning, acquisition and replacement involve large capital investments, often supported by external capital investment grants. Conversely, built asset maintenance BAM activities need to be funded through internal organisational revenue. Even though organisations recognise buildings as a critical asset to fulfil organisational strategic objectives, their views on investments on BAM is somewhat arbitrary, with priorities generally reflecting available organisational budget rather than strategic need. Chalifoux and Baird, (1999, cited in Njuangang et al., 2016) claimed that, due to the lack of understanding of the science of maintenance, organisations rely on the old tenet "if it isn't broken, don't fix it". In a relatively recent study, Jones and Sharp (2007) claimed that many organisations see maintenance of built assets as a cost burden, rather than a value addition to the organisation. One reason for this could be associated with a lack of evidence and business tools (when compared to those available for major BAM decisions related to acquisition, disposal or replacement of built assets ) to align BAM activities with organisational performance. For example, capital investments within NHS organisations in England are well supported by best practice guidance, such as the NHS England business case approvals process (Department of Health, 2013) and the Capital Investment Manual (Department of Health, 1994), which facilitate strategic considerations including the development of the business case and wider stakeholder consultations. Conversely, there is very little national-level guidance to optimise strategies for day to day maintenance activities within estates and facilities divisions, which are primarily developed based on past experience. Whilst this approach might be reasonable whilst annual budgets are growing, during financially difficult times, organisations tend to compromise the priorities given to BAM activities over other clinical activities within hospitals (National Health Executive, 2016) and the maintenance backlog begins to build. In order to defend maintenance budgets, built asset managers need a range of decision support tools to prioritise BAM activities and investigate maintenance patterns of specific elements, components and systems within buildings. This paper presents a) a conceptual framework for how Building Information Modelling (BIM) can integrate a wide range of interdepartmental information streams in a way that aligns BAM decisions to organisational performance; b) details a pilot study showing how the proposed framework could be implemented within healthcare organisations via a cloud-based BIM application developed for a selected healthcare organisation.

\section{Building Information Modelling and existing use of Information and Communications Technology}

Information and Communications Technology (ICT) is not new to the construction sector.

Communicating building related information electronically via CAD (Computer Aided Design) systems has existed since the 1980s (Day, 2002). Since the early 1990s, object oriented CAD was used to simplify building section drawings by linking building graphics with non-graphical data on common building elements (ibid). Facilities management substantially uses ICT for different purposes. A variety of tools such as spreadsheets, Computerized Maintenance Management Systems (CMMSs), Computer-Aided Facility Management (CAFM) systems, Document Management Systems (DMSs), Building Management Systems (BMSs), and Building Automation Systems (BASs) are used to manage facilities (Parsanezhad and Dimyadi, 2014). In particular, CMMSs are used for asset maintenance activities. Basic functionalities of CMMSs include scheduling, recording and control of maintenance activities, generation of service requests, managing work orders, calculating and tracking resource requirements for executed maintenance activities, as well as allowing for the tracking of past maintenance activities (Sapp, 2013 cited in Parsanezhad and Dimyadi, 2014; Duran, 2011). In addition, these systems can also store information such as asset records, stock records, condition of assets, etc. CAFM systems are used for functionalities such as space management, maintenance and operation planning, facility budgeting and accounting, construction and project management, space inventory and management, architectural and interior planning, space forecasting, 
telecommunications and cable management, lease and property management, and furniture and equipment management (Keller and Keller, 2004; Elmualim and Pelumi-Johnson,2009). The use of these ICT systems for asset management help organisations to improve the efficiency of their AM and FM activities by reducing administration related processing times and errors (Elmualim and Pelumi-Johnson, 2009). However, many organisations are not satisfied with the capabilities of their implemented asset management systems (Duran, 2011). Literature suggests that these systems could be further improved through the integration of a variety of hardware and software components (Elmualim and Pelumi-Johnson, 2009) to provide more advanced applications (Duran, 2011), which would be capable of system diagnostics, decision reasoning, and seamless data collection and transfer from and between other systems (Duran, 2011; Elmualim and PelumiJohnson, 2009).

Building Information Modelling (BIM) is one of the latest applications of ICT technologies to the construction sector. A former UK government initiative, the BIM Task Group (2017) defined BIM as "value creating collaboration through the entire life-cycle of an asset" and "exchange of shared 3D models and intelligent, structured data attached to them". Whilst BIM has the potential to improve information modelling throughout the building life cycle, literature suggests that BIM has received more attention, and is most often used, in the early stages of the building life cycle with progressively less use seen at the latter stages (Eadie et al., 2013; Becerik-Gerber et al., 2014). BIM was initially deployed as a solution to tackle design and construction phase issues such as lack of productivity, efficiency, and time and cost savings through improved communication (Arayici et al., 2012). Arayici et al. (2012) found that at the design stage the key management and communication problems, such as poor quality of construction works, unavailability of materials, and ineffective planning and scheduling, could be mitigated by adopting BIM. Through a case study into the construction phase, Davies and Harty (2013) found that the main contractor on the project developed BIM-enabled tools to allow site workers to use mobile tablet personal computers to access design information and to capture work quality and progress data on-site.

Whilst existing ICT systems such as CAFM and CMMSs support and benefit BAM in numerous ways, their functionality can be improved if they take advantage of BIM. For example, in the case of maintaining healthcare built assets, there is the need to process large sets of complex information, gathered through different stakeholders using multiple data feeds (Pärn et al., 2017; Gnanarednam and Jayasena, 2013). Whilst existing ICT systems can store this data, the lack of software interoperability complicates data transfer and sharing and often results in a loss of data richness that inhibits the performance of BAM systems (Pärn et al., 2017). Liu and Issa (2014) also highlighted the importance of readily available information, such as manufacturer information and equipment manuals to improve the efficiency and accuracy of BAM activities. Again, BIM models can provide a centralised and rich information store to facilitate data retrieval and transfer between different ICT systems used for BAM. Further, BIM can improve efficiency of BAM activities by reducing the manual processing of information handover, increasing accuracy of data and again improving decision maker's accessibility to this rich level of data (Kassem et al., 2014). Finally, BIM can help organise the very large volumes of 'real-time' data now being produced by building monitoring system, that, if not managed effectively could overwhelm users, rather than help them to detect deficiencies and make better decisions (Gnanarednam and Jayasena, 2013; Evchina and Lastra, 2018). BIM can contribute to automate data analysis, which is limited within existing basic CAFM systems (Pärn et al., 2017). Finally, and potentially more importantly, BIM functionalities can support strategically driven decision making for BAM. Basic ICT systems used for BAM do not store information supporting strategic decision making associated with BAM (Alexander, 2000 cited in Gnanarednam 
and Jayasena, 2013; Keller and Keller, 2004) and this limits senior manager's ability to use them for strategic decisions making (Gnanarednam and Jayasena, 2013). However, improved CAFM systems have been used to support strategic decision making. For example, Keller and Keller (2004) developed a strategic master planning application to improve the capabilities of a CAFM system used by a large scale organisation following $9 / 11$ attack. This tool provided a single data source for facilities information and was capable of streamlining of documentation and records, making more data available for decision making without duplicating files and efforts.

Currently, COBle (Construction Operations Building Information Exchange) and IFC models (object orientated 3D vendor-neutral BIM data format for the semantic information of building objects (Pärn et al., 2017)) are used as the file format for transferring BIM data into CAFM tools. However, whilst there would appear to be many advantages of moving from a CAD approach to a BIM approach to BAM; there are also fundamental challenges that need to be addressed if these potential advantages are to be realised. Not least of these challenges is the need for industry to move away from the 'silo mentality' of individual discrete disciplines with their proprietorial working practices and data regimes, to a whole industry view where inter-disciplinary practices, based around shared data and information models prevail (Arayici et al., 2012). However, achieving this shift involves a major change management task, and exposes organisations to high risks (Khosrowshahi et al., 2012). Haron (2013) and Davies and Harty (2013) found that the main problems that were preventing the construction industry from embracing BIM were rarely technical but related more to the management and people issues, which underpin the capability of an organisation to successfully implement BIM solutions. Therefore, successful BIM adoption needs to have senior management support and be underpinned by sound implementation strategies (Arayici et al., 2012).

\section{BIM and healthcare built asset maintenance}

The National Health Service (NHS) is one of the UK's largest public sector organisations, operating over 1,200 hospitals and nearly 3,000 other treatment facilities. The NHS occupies a floor area of 24.3 million $\mathrm{m}^{2}$; the equivalent to nearly 3,500 football pitches; and in 2016, the total cost of running the NHS Estate was approximately $f 8.3$ billion (Department of Health, 2016). This includes costs associated with estates and facilities finance (such as PFI leases), hard FM (maintenance of buildings, land and assets) and soft FM (hotel services). Since hospital buildings are critical infrastructure built to provide care, much of the maintenance in the healthcare estate needs to be properly planned. However, changing care needs and statutory requirements mean that a mix of planned and reactive maintenance is a more feasible maintenance management strategy (Chanter and Swallow, 2008).

Much of the research related to how BIM is used in the practice of healthcare BAM has been done by Shohet and Lavy and his team (Lavy and Shohet, 2007; Lavy and Jawadekar, 2014). For example, Lavy and Jawadekar (2014) investigated how 3D models for existing built assets could support maintenance and refurbishment decision making and the authors found that keeping the as-built data in a digital form could avoid re-creating it for subsequent repair and maintenance work. Further, significant time savings can be made through the rapid creation of drawings, clash detection, quantity take off, cost calculation or cash flow modelling, scheduling, sub-contractor and supplier integration and creating and digitally updating assets (Becerik-Gerber et al., 2011). Under the proposed new arrangements for the UK healthcare sector (procure22.nhs.uk, 2017), Principle Supply Chain Partners (PSCPs) will have to handover all required documentation, data under GSL requirements, BIM data and CDM documentation, before the scheme is certified as completed. (Redmond, 2016). Some NHS trusts have used BAM BIM to manage built asset related information. 
For example, BIM is being applied to the redevelopment of Wrightington Hospital in order to enable the launch of estate and built asset management systems capable of handling the complexity of the hospital's operational requirements. Wrightington Hospital intend to use electronic project and built asset information, documentation and data to assist built asset operational activities. Another example is The Barts \& London Hospital BIM and interactive model, which can be used to: check for safe access for operation and maintenance; confirm major plant and medical equipment installation/removal strategies; link to construction programmes; and monitor project progress.

Even though, specific healthcare related case studies were not identified, generic BIM literature suggests that asset management BIM could facilitate some advanced functionalities associated with performance monitoring and simulation of buildings and their systems. These include, energy/thermal analysis and control, carbon foot printing, performance measurement and monitoring through sensors, structural analysis, environmental analyses, and day light simulation (Volks et al., 2014; Carbonari and Jones, 2014). From existing literature, it is clear that current built asset management BIM research is limited to modelling physical assets and to some extent evaluating the performance of physical assets. However, linking BAM activities with overall organisational performance is essential to ensure built asset management investments add value to the core business of an organisation. To this end BIM has the potential to integrate a wide range of data streams and integrate these with business strategies. For example, Carbonari and Jones (2014) reported that BIM is used to evaluate alternative space management strategies in combination with user behaviour modelling based on end-user feedback. However, limited attempts have been used to draw organisational performance data and link BAM strategies and activities with organisational performance in healthcare settings. The research reported in this paper therefore investigated how organisational performance data could be integrated into a BAM BIM system for the UK healthcare sector.

\section{Built Asset Maintenance}

Maintenance of built assets is traditionally viewed as works necessary to keep, restore or improve the performance of building structure, fabric and components and basic engineering installations to acceptable standards, and sustain the utility and value of built assets (Seeley, 1976). Literature (BIFM, 2018; BSI, 1993) reveals two key approaches to BAM.

1. Planned and preventive maintenance activities: these refer to maintenance activities identified, organised and carried out with forethought to a predetermined plan at predetermined intervals of time. These activities are primarily identified through building condition surveys or cyclical maintenance demands.

2. Reactive maintenance activities: these refer to maintenance activities carried out to no predetermined plan, but in response to failures or emergency situations.

For many organisations their BAM activities are based on: condition surveys; cyclical maintenance demands for built assets or; on statutory requirements. Healthcare buildings in the UK undergo a six facet condition survey approximately every five years. This non-mandatory survey is conducted by building surveying professionals and assesses the physical condition of the estate's built assets and their compliance with mandatory fire safety requirements and statutory safety legislation. The survey enables organisations to allocate condition rankings to approximately 223 building elements/components for each building. This traditional physical condition based approach to BAM has its own weaknesses and has been criticised by many scholars. Major criticisms includes (as summarised in Sherwin, 2000; Tsang, 2002; Jones and Sharp, 2007): 
- $\quad$ Physical Condition Based Maintenance (PCBM) at best will allow buildings to perform to original capacity with just incremental improvements, and does not consider the dynamics of organisational (technological and functional) demands.

- $\quad$ PCBM demand invariably exceeds funds available for maintenance, and PCBM fails to provide the link between BAM investment and organisational performance. Hence, organisations are reluctant to spend on maintenance, causing further increase in backlog maintenance, built assets failing to operate at maximum capacity, and potentially leading to a spiral of decline.

- $\quad$ PCBM does not facilitate communication between building managers and users, nor does it consider user concerns within the maintenance strategy/programme.

- $\quad$ PCBM is prone to confirmation bias, including unrealistic surveys compiled by those doing the survey, an inability to predict long term cost requirements and inform long term maintenance planning, and poorly links to business objectives.

- Traditional approaches to maintenance management lack a feedback loop to learn lessons from mistakes.

For these reasons many organisations see maintenance of built assets as a cost burden that does not add value to the organisation. Consequently, the priority given to built asset investment falls within organisational budgets causing a backlog of maintenance, which can ultimately lead to a spiral of decline and disrepair (Arditi and Nawakorawit, 1999 cited in Jones and Sharp, 2007).

\section{Value addition through BAM}

Støre-Valen and Lohne (2016) identified that considerations into life cycle costs and adaptability, and strategic involvement of facilities management could contribute to added value for healthcare organisations. However, strategically aligning BAM activities with overall organisational performance is challenging and requires an understanding of the relationships between the organisation's key performance indicators and its BAM plans. A good performance measurement system should be multi-dimensional and be able to measure performance of the overall business across both organisational functions and hierarchies (Neely, 2002). There are many performance measurement frameworks available for organisations to measure their success. For example, performance measurement approach developed by Keegan, Eiler and Jones (1989) emphasised the importance of integrating cost and non-cost dimensions as well as internal and external dimensions into an organisation's performance model. The widely accepted balanced scorecard framework developed by Kaplan and Norton (1992) identified four different ways of looking at performance: financial; customer; internal business; and innovation and learning perspectives. Brown (1996) in his Macro Process Model of the organisation suggested that the performance of an organisation should be measured through five stages leading to the core business: inputs; processing systems; outputs; outcomes; and goals. Brown's (1996) model is probably the most appropriate performance model for healthcare organisations, since healthcare organisations are complex and the services they provide are diverse (Støre-Valen and Lohne, 2016). In such systems performance should not be measured solely against ultimate outcomes but also against business processes where each stage of the overall system is the driver of performance for the next stage (Brown, 1996). Brown (ibid) also proposed that benchmarking input and processing dimensions could result in better outputs and outcomes. Raleigh (2012) also stated that outcome performance indicators are best for monitoring progress on performance goals, but input and process indicators are best to control and drive improvements.

Literature often uses terms such as 'quality of healthcare', 'health outcomes', and 'performance' to denote healthcare organisational performance. Parameters associated with these terms often represent ultimate goals and outcomes of the health service. Between them the World Health Organisation (2006), the Institute of Medicine USA (2001), the Council of Europe (1998) and the UK NHS all identified a series of healthcare quality dimensions: effectiveness; efficiency; efficacy; access; 
safety; responsiveness; equity; acceptability; timeliness; caring; appropriateness; patient satisfaction; patient-centeredness; and good leadership that would be expected of a healthcare system. Recently, the NHS in its five-year forward view (2015-2020) identified three key aspects to define quality in health care: patient safety; clinical effectiveness; and patient experience. In addition, health service performance is also measured through operational and output performance of individual organisations. For example, the NHS measures its performance through indicators such as procedure lengths and waiting times. In their quarterly publication, NHS Improvements assess and publish healthcare organisations' operational performance against A\&E waiting times, referral to treatment times, cancer treatment times, ambulance response times, access to mental health services and progress on implementation of seven-day services. In addition, the National Institute for Health and Care Excellence (NICE) publishes quality standards in the form of statements, with accompanying metrics, designed to drive and measure quality improvements for different areas of care (e.g. Acute heart failure, Acute kidney injury).

Inputs to healthcare service are the resources needed to perform processes and provide intended services. These include financial resources, physical infrastructure such as buildings and assets, ICT infrastructure, supplies and equipment and staff. Thus, as a key input resource to the health service, effective BAM can contribute to improve the performance of the healthcare service. In his widely known first scientific research in this area, Ulrich (1984) studied the restorative effect of natural views on surgical patients in a Pennsylvania hospital and concluded that patients who had views to nature through windows took less pain medication compared to other patients in the control group. An ensemble of similar research under the term of 'Evidence-based design of healthcare buildings' endorse the view that built assets can improve the performance of the healthcare service (Ulrich et al., 2008; Codinhoto et al., 2009; Phiri, 2006). However, contemporary approaches of measuring BAM performance and BAM decision making do not necessarily take a holistic approach to improve the operational, outcome and output performance requirements of the health service. For example, Lavy et al. (2010) in their facilities management performance model identified that FM performance is measured under following four categories:

(1) Financial indicators (FM cost, current replacement value, maintenance backlog, capital renewal and maintainability);

(2) Physical indicators (physical condition degree, resource consumption, indoor environment, property and real estate);

(3) Functional indicators (productivity, space utility, adequacy of space and logistics); and

(4) Survey-based indicators (POE, learning environment, community and appearance).

Reasons for the limited alignment of FM performance with operational and outcome performance is associated with a lack of methods and tools to justify the contribution from built-asset maintenance expenditure to core business goals (Steinke et al., 2010) and lack of data and information sharing to facilitate such links. One of the fastest growing problems in any organisation is the lack of essential information to make informed decisions (Agerwal and Hauswald, 2010). This is particularly true for real estate management, where there is lack of formal strategies for information gathering and knowledge sharing (Fong and Lee, 2009). Lucas et al. (2013) found that there were no links between facility information and clinical information to aid effective decision making. To fill this gap Lucas et al. (2013) developed a product model that linked facility information with clinical information to better manage patient safety threats and hazards.

The research report in this paper proposes that the digital capabilities associated with BIM can facilitate effective information gathering and knowledge sharing within an organisation to link BAM activities to organisational performance and hence improve BAM decision making. In summary, this research propose the following framework (see Figure 1) which intends use BIM capabilities to 
measure and link overall healthcare organisational performance, performance of BAM and input resources used to facilitate BAM to make better informed BAM decisions.

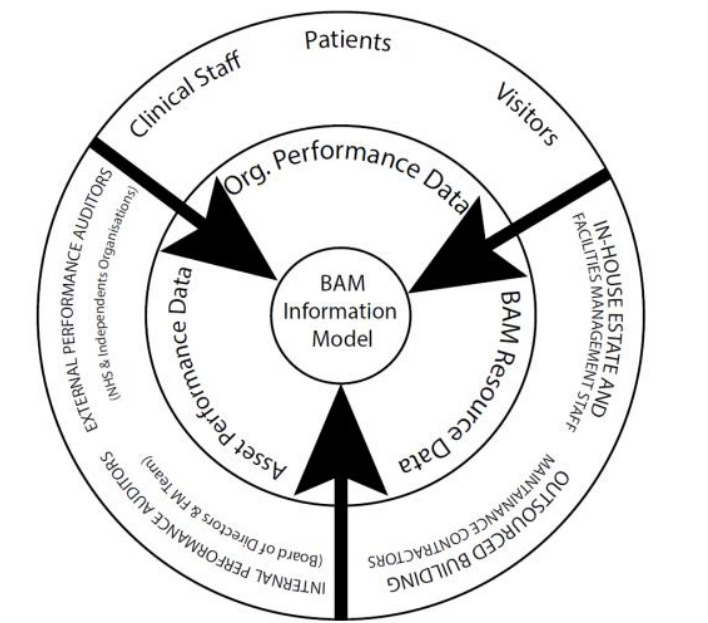

Figure 1: Digitally integrating a wide range of information to support BAM decision making

\section{Research methods}

A participatory case study was undertaken with a regional NHS hospital to: review the type of information that can be used to better inform BAM decision making; to test how the conceptual framework can be applied within a BAM division of a healthcare organisation; and to develop a cloud-based BIM application. The selected hospital had a varied building portfolio and it was purposefully selected to provide easy access to a rich set of data. The selected hospital managed most of its BAM activities with in-house operatives, supervisory and management staff. The participatory case study was designed with multiple data collection points and outputs explained below. The participatory case study research programme took place between June 2016 and April 2017.

- An initial focus group with key BAM stakeholders of the organisation was used to identify: a) types of data and information used for current practices of built asset management activities; b) other information available within the organisation that could be used to improve BAM decision making and c) to establish typical/potential BAM division's requirements of a BAM BIM model. The focus group was attended by four BAM professionals from the hospital.

- Published literature from the Department of Health, the NHS, and other related publications were reviewed to identify data and information gathered within NHS hospitals that can be used for better BAM decision making. This review was particularly useful in identifying healthcare performance related data gathered within non-estate departments.

- A cloud-based BIM application (system architecture) was developed to integrate BAM performance data with BAM resource data and healthcare performance data to support better informed BAM decision making. BAM practices pertaining to the maternity ward of the hospital was integrated into this application, since the hospital had a partially completed 3D (revit) model for this space.

- In parallel, five subsequent face-to-face interviews with AM professionals in the estates department were conducted to fill gaps in the initially collected data (focus group and document review) on BAM procedures and maintenance records required to develop the cloud-based BIM model. These short interviews were conducted as and when new data gaps were identified during the BIM model development phase. Hypothetical information was 
used in the model when existing hospital maintenance records lacked the detail required to develop the BIM model.

- Finally, the cloud-based BIM model was populated with data and validated through a demonstration of the model to four BAM professionals of the hospital who participated the initial focus group. Integrating the Revit model into the cloud-based application in an interactive form was extremely resource intensive. As such, for demonstration and validation purposes, the final version of the cloud-based BIM application consisted of data pertaining to a selected shower room within the maternity ward. A shower room was selected since, it involved BAM activities representing a variety of trades such as plumbing, electrical systems, alarm and warning systems; and BAM activity records of the hospital showed that shower rooms require frequent maintenance compared to other spaces within the hospital. The application was validated with the feedback from the BAM professionals of the hospital.

One of the limitations of this research is that the final BIM application was developed for only one shower room. Even though the core structure of the application provides the ability to select all or multiple spaces within the hospital (on a 2D plan) and provide functionalities to manage the overall estate of the hospital, if the application was tested further for more spaces within the hospital, more issues associated with FM BAM would have been identified. Further, the application was validated with the feedback from the BAM professionals only. Further research is required to investigate perspectives from other departments of the hospital (specifically clinical departments) related to interdepartmental data and information sharing and to validate this pilot application using the feedback from a different hospital.

\section{Results}

\section{Current practice of information gathering and sharing and BIM potential}

Healthcare organisations conduct a number of performance audits related to the physical performance of built assets, built asset management resource data, and built assets' impact on quality of care (see Table 1). It can be seen that organisations possess a significant level of such information gathered via various performance audits which provides evidence of the performance of individual spaces, elements or buildings. However, the richness and details of these data collections are lost when they are compiled into final assessment reports which are shared between senior managers of the organisation and external organisations. Digital capabilities associated with BIM can share and integrate information gathered within various departments of NHS hospitals to retain its richness and facilitate better informed BAM decisions. In particular, BIM can be used to store these detailed data attached to individual spaces, elements or buildings to facilitate advance analyses. For example, the building condition survey is an assessment of the physical condition of estates. During this comprehensive survey, surveying professionals observe and investigate individual elements of each building. However, these are then compiled to produce an overall summary results for the estate and the specific details are often lost. BIM capabilities and tools can preserve the richness of these data by storing survey results in detail as and when the surveying team investigate the physical condition of individual spaces, elements or buildings. 
Table 1: Data that could be used for built asset management decision making

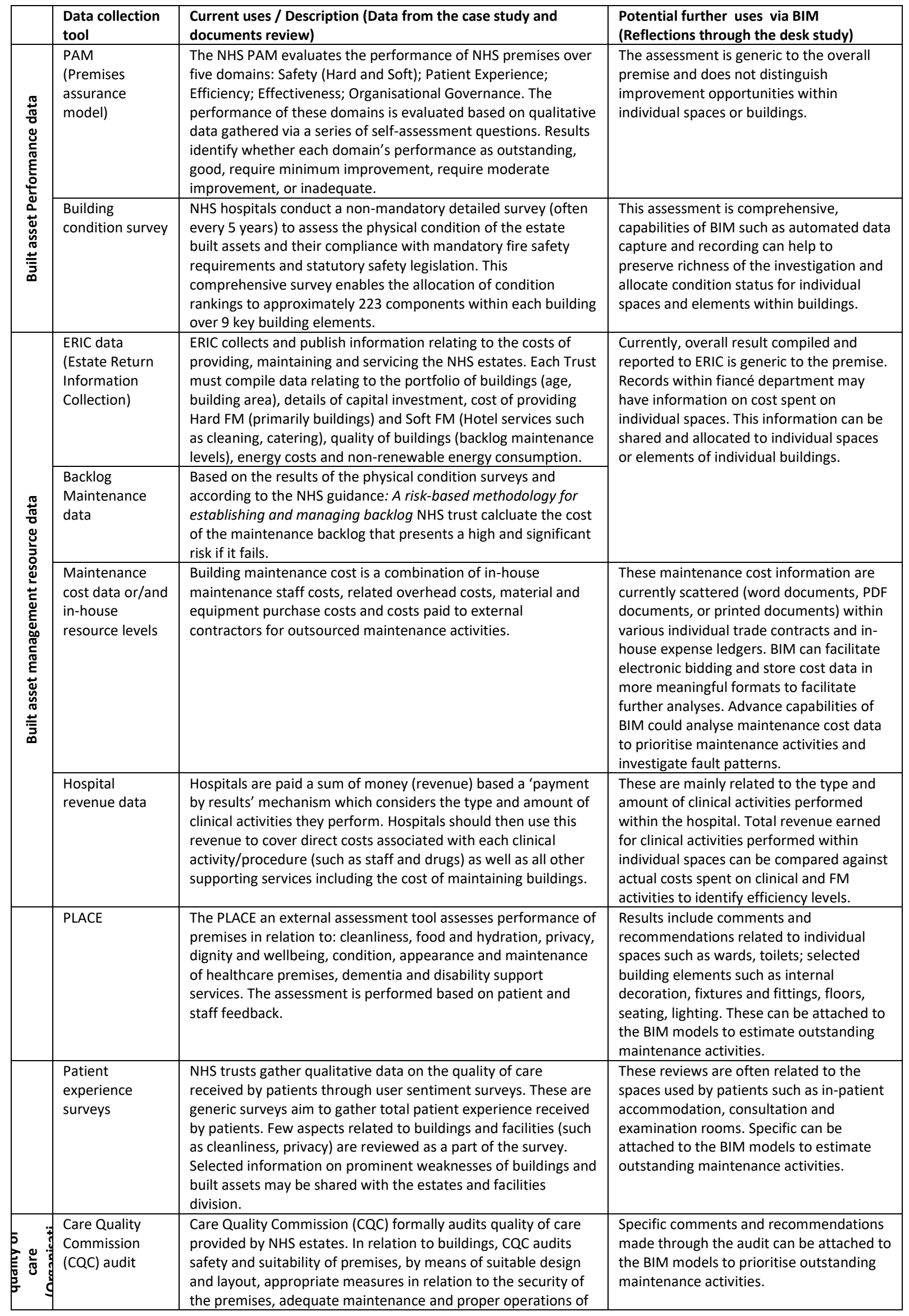




\begin{tabular}{|l|l|l|l|}
\hline & premises and grounds. & \\
\cline { 2 - 3 } $\begin{array}{l}\text { Locally } \\
\text { maintained } \\
\text { health and } \\
\text { safety records }\end{array}$ & $\begin{array}{l}\text { All NHS trusts must record all health and safety incidents. } \\
\text { Incidents record protocols are generic to the premises, } \\
\text { however, description contain information that could identify } \\
\text { the location/space of incidents. }\end{array}$ & $\begin{array}{l}\text { Specific comments and recommendations } \\
\text { made through the audit can be attached to } \\
\text { the BIM models to prioritise outstanding } \\
\text { maintenance activities. }\end{array}$ \\
\cline { 2 - 3 } NRLS data & $\begin{array}{l}\text { More formally, the National Reporting and Learning System } \\
\text { (NRLS) collect confidential reports of patient safety incidents } \\
\text { from healthcare staff across England and Wales. According to } \\
\text { NRLS statistics (2016), around 6.6 \% of total incidents have been } \\
\text { directly attributable to physical and organizational structures } \\
\text { and facilities. }\end{array}$ & \\
& & \\
\hline
\end{tabular}

Healthcare organisations currently conduct number of internal and external audits to investigate the quality and safety of the care they provide. These audits contain comments and remarks related to the performance of buildings and assets (e.g. staff complaints on lighting levels, slips and trips associated with floor finishes etc.). If this information is shared with estates and facilities divisions, it can be used as evidence to align BAM activities with organisational performance.

\section{The BIM application to integrate a wide range of information for BAM decision making}

This research developed a cloud-based BIM application to demonstrate how a wide range of interdepartmental information can be integrated to make better informed decision during the maintenance management of a shower room space. Three types of data pertaining to a series of maintenance activities were attached to the cloud-based application to show its capabilities.

Physical condition of built assets/built asset performance data: Maintenance activities were primarily identified from the maintenance history of shower rooms within the hospital. Some hypothetical maintenance activities were added in order to represent maintenance activities related to different elements and engineering systems.

Maintenance resource data: Supplementary details such as cost and time required to restore each maintenance activity, risk to the healthcare service delivery if these activities are not restored, and details of the in-house staff and external trade contractors responsible for each maintenance activity were added to the BIM application. Actual costs associated with maintenance activities were commercially sensitive; therefore this model used BCIS (Building Cost Information System) published cost data for maintenance activities. The risk rating is based on expert judgement made by the estates and facilities team.

Organisational performance data: These are the details primarily expected from clinical departments based on staff and user feedback. These details were not formally shared with the estates and facilities division. Some comments were identified through BAM job details and some hypothetical comments were incorporated in the application.

As identified in the literature review, during financially difficult periods, the case study organisation found it difficult to secure enough funding to conduct all of its BAM activities. Therefore, evidence that could support prioritising BAM activities was useful.

The cloud-based BIM application was designed to facilitate three functionalities. These were the key BIM system design requirements identified through the focus group with the case study organisation and through the literature review.

1. Prioritise outstanding maintenance activities of the shower room based on rectification costs of activities and the risk that each outstanding work item was to service delivery. This can benefit the organisation in two ways. First, these analyses can inform strategic decisions such as allocation of budget, decision to refurbish or replace. Secondly, at the operational level, this 
analysis can be useful to prioritise maintenance activities to suit a budget for built asset maintenance.

2. Establish maintenance patterns by analysing completed maintenance work over a period of time. In particular, these patterns can identify cost and resource significant elements/components within the organisation's estate by analysing costs and times of maintenance activities. This pattern analysis in turn can inform further options appraisals and strategic maintenance decisions such as replacing or refurbishing individual elements/components.

3. Locate individual elements/components with backlog maintenance and retrieve as-built information and repair and maintenance histories of these elements. This data can be used to analyse the effectiveness of individual elements/ components as well as to supplement new job tasks for individual elements/components.

Due to limitations of current information gathering sharing practices within the healthcare organisation, the BIM application developed for this research could not incorporate all the potential functionalities conceptualised in Table 1 above. Two key changes in current practices are required in order to fully develop the in-use phase BIM applications proposed in this research. They are: better interdepartmental data sharing, particularly in digital formats: and the automation of data feeding and sharing. At present, the estates and facilities division of the healthcare organisation primarily rely on information gathered by itself and through their auditing processes. However, as discussed above, BAM decision making can be supplemented with information gathered in clinical departments and other administrative departments such as finance. Hospital revenue data can be allocated to individual spaces or buildings and can be compared with actual cost spent towards clinical and FM activities. These analyses may be useful to identify needs for major refurbishment within spaces or even justify the business case for a new building. However, interdepartmental data sharing will be difficult and complicated unless data is collected and stored in easily sharable digital formats that could be filtered and attached to BIM models. This is one of the weaknesses of currently used computer aided facilities management system. Whilst current systems are capable of storing and analysing a reasonably large volume of information: they are not designed to communicate with other cloud-based systems within the organisation; and pose a significant burden of manual data handling if large volumes of information need to be entered and stored within the systems. Therefore, cloud-based data stores used within organisations need to be improved to support automation of data feeding and sharing between various information systems within hospitals. Even though the BIM application presented in this paper is tailor-made to the participatory hospital, considering its building spaces and BAM practices, this pilot research found a few generalizable findings.

- $\quad$ BIM supplemented with ICT capabilities could provide a wide range of interdepartmental data to support organisational performance oriented BAM decision making.

- Hospitals currently gather a significant level of data and information (as presented in Table 1) and these could be shared to improve BAM practices. Data collection practices within other departments could be widened to gather useful data to further improve BAM decision making.

- Subsequently, implementation of BAM BIM will require support from and changes within the whole of the organisation. These may include the development of protocols to facilitate interdepartmental data sharing and an effective Human Resources approach to handle change management.

Discussions and implications

Dilemma of tenure and sponsorship 
Implementation of BIM at the in-use phase of buildings faces a dilemma of tenure and sponsorship. At the design and construction phase of the building life cycle BIM primarily contains information that has been generated by those directly involved with the design and construction process. As such the information is generated as a primary output from the project (particularly for public sector projects in the UK where the development of a BIM was a required part of the project process) and paid for through the construction project's budget. However, once the building is constructed and commissioned, it is passed to the client organisations, which in most cases operate with a small estate and facilities division responsible for the management of the building, but do not normally have a direct labour force for maintenance or construction activities. As such, whilst the estates and facilities management division may have a strategic interest in using the BIM solution to support their BAM activities, it does not have either the human or financial resources to maintain the BIM solution. As consequence, the BIM solution can rapidly become obsolete unless its application can gain support from other, non-construction (primary business) divisions, within the organisation. In NHS hospitals gaining support from primary business divisions is exacerbated by the lack of estates and facilities management professionals at senior management or executive board level Rees (1997 cited in Shohet and Lavy, 2017). Without a champion arguing the case for the use of BIM to drive organisational performance BIM is unlikely to attract sufficient central funding or time commitment from key primary divisions to provide the rich data that BIM relies on to develop the relationships that link BAM to operational performance. However, without this commitment the use of BIM to link BAM to organisational performance it is unlike to be realised and it is likely that BIM will be seen as yet another maintenance orientated cost burden to be borne by the organisation. This is the dilemma facing those advocating the use of BIM as part of BAM. Unless BAM is viewed as a major contributor to improved organisational performance, it is challenging to justify the time and cost resource needed to maintain the design and construction phase of a BIM solution throughout the in use phase of the building life-cycle. However, without investing time and money in BIM it will be impossible to demonstrate that organisational performance improvements can be delivered through BAM programs. This is where small scale research and development projects like the one described in this paper can play a part by demonstrating the potential of BIM BAM without the need for major investments.

\section{What is "FIM"?}

BIM is often described as 3D models of buildings to which intelligent, structured data is attached. However, this research poses the question as to whether BIM during the BAM and operational phase of buildings should instead be focused on data sharing and information modelling rather than 3D visualisations of the building? Whilst 3D models are useful to support maintenance and refurbishment activities, the authors would argue that integrated models of the interaction between the BAM resource consumption, performance of BAM components/units and overall organisational performance are more important for BAM strategic decision making. As discussed throughout this paper the effectiveness of these decisions are dependent on the level and type of information available to BAM decision makers, and the availability of sophisticated tools capable of analysing such information. This is particularly true for organisations such as healthcare, which have a diverse building portfolio and where overall organisational performance is always under scrutiny. For such organisations the key challenge in linking BIM to BAM is to develop investigative tools (particularly pattern matching tools) and multi-criteria models capable of intelligently analysing BAM and organisational performance data. Similar to work of Keller and Keller (2004), the possibilities of integrating such intelligent tools with existing or improved CAFM systems and CMMSs should also be explored with the view of developing applications with intelligent functionality as part of a Facility Information Modelling (FIM) solution. 


\section{Implications}

Interdepartmental data sharing is a key to implementing BIM for BAM. However, achieving this will require healthcare organisations to digitalise all data gathering processes and centrally store this data in a format that can then be shared with other departments within the organisation. To support such a data store the authors suggest the need to develop platforms similar to COBle or IFC to ensure the seamless transfer of centrally stored data into various BIM and other ICT applications in readable formats. Evidence and information alone do not make effective strategic decisions. BAM specific guidance and supplementary tools similar to the NHS England business case approvals process (Department of Health, 2013) and the Capital Investment Manual (Department of Health, 1994) should be developed to assist BAM professionals in strategic decision making and reporting. In particular, these can increase awareness of how BAM could facilitate overall organisational performance improvements. However, developing the technology to support interdepartmental data sharing in digital formats and developing intelligent BIM tools will be very resources (both time and cost) intensive and in a time of financial constraints, will require significant support form senior management. To this end cost/benefit analyses may be useful to quantify improvements to organisational performance and demonstrate the resultant value added through such investments.

\section{Conclusions}

This research contributed to the knowledge of BAM by proposing and piloting a framework on how BIM can facilitate modelling and analysis of a wide range of interdepartmental data to provide evidence to make BAM decisions to improve healthcare organisational performance. A good BAM strategy needs to align BAM activities to support overall organisational performance and its key business goals and objectives. This requires built asset managers to use constant feedback of performance related information from divisions outside of asset management. Healthcare organisations currently gather a wide range of such information that could be integrated through enhanced digital capabilities. These include information related to physical performance of built assets, built asset management resource data, and built assets' impact on quality of care. Some data gathered within clinical departments contains specific remarks related to how built assets contributes to the overall organisational performance.

Since, current use of BIM for built asset management is mostly related to a continued use of construction phase BIM models to facilitate repair and refurbishment activities, many organisations still see BIM as a supporting tool within the estates and facilities division. However, as investigated in this research, BIM can integrate a wide range of information to link BAM activities with organisational performance. However, sharing of data and information between various audits and between various departments is limited. Manual handling and feeding of data into existing ICT systems is a significant burden to estates and facilities division and prevents the use of existing ICT systems to their full potential. Therefore, if the wider potential of BIM to improve organisational performance is to be realised new procedures for gathering and sharing data and information need to be developed. To ensure interoperability these new procedures should follow standard protocols that support integrated organisational performance models and interdepartmental data sharing. Once such integrated models are developed then BIM BAM will become relevant to other divisions of the organisation and this in turn will raise its status from a cost-burden to a value-adding activity. However, the effort required to develop such BIM BAM solutions, particularly the organisational level change management tasks, should not be underestimated. At this point senior management commitment will be essential, as significant budgets will need to be invested.

\section{Acknowledgements}


The work was funded by Royal Institution of Chartered Surveyors. The authors also wish to acknowledge the Princess Alexandra hospital who participated in the case study. 


\section{Reference}

1. Agerwal, S. and Hauswald, R. (2010), "Distance and Private information in lending”, Review of Financial Studies, Vol. 23 No. 7, pp. 27757-32788.

2. Arayici, Y., Egbu, C.O. and Coates, S.P. (2012), "Building information modelling (BIM) implementation and remote construction projects: issues, challenges, and critiques", Journal of Information Technology in Construction, Vol. 17 , pp. 75-92.

3. Becerik-Gerber, B., Jazizadeh, F., Li, N., and Gulben, C. (2011), "Application areas and data requirements for BIM-enabled facilities management", Journal of Construction Engineering and Management, Vol. 138 No 3, pp. 431-442.

4. BIFM, (2018), Facilities Management Glossary. Available at: https://www.bifm.org.uk/bifm/knowledge/Glossary (accessed 18 August 2018).

5. BIM Industry Working Group, (2011), BIM Management for value, cost and carbon improvement: A report for the Government Construction Client Group Building Information Modelling (BIM) Working Party Strategy Paper. UK. Available at: https://www.cdbb.cam.ac.uk/Resources/ResoucePublications/BISBIMstrategyReport.pdf/view_(accessed 18 August 2018).

6. BIM Task group. (2017), What is Building Information Modelling (BIM)? UK. Available online: http://www.bimtaskgroup.org/bim-faqs/, (accessed 18 March 2017).

7. BSI, (1993), British Standard BS 3811: 1964 - Glossary of Maintenance Management Terms in Terotechnology, British Standards Publishing Ltd, UK.

8. Carbonari, G. and Jones, K. (2014), "Sustainable Facilities Management through Building Information Modelling", International Journal of Facility Management, Vol. 6 No 1, pp. 214-223.

9. Chanter, B. and Swallow, P. (2008), Building Maintenance Management, Blackwell Publishing, Oxford.

10. Chapman, K. (1999), "Dissatisfaction with stock condition surveys in social housing", Structural Survey, Vol. 17 No 4, pp. 211-5.

11. Choo, C., Wei-Bergeron, P., Detlor, B. and Heton, L. (2008), "Information culture and information use: an exploratory study of three organizations", Journal of the American Society For Information Science and Technology, Vol. 59 No. 5, pp. 1-13.

12. Codinhoto, R., Tzortzopoulos, P., Kagioglou, M., Aouad, G. and Cooper, R. (2009), "The impacts of the built environment on health outcomes", Facilities, Vol.27 No.3/4, pp. 138-151.

13. Davies, R. and Harty, C., (2013), "Measurement and exploration of individual beliefs about the consequences of building information modelling use", Construction Management and Economics. Vol. 31 No. 11 , pp. 1110-1127.

14. Day, M. (2002), "Intelligent Architectural Modelling”, AEC Magazine, September 2002.

15. Department of Health, (1994), Capital Investment Manual. Leeds, UK.

16. Department of Health, (2013), The NHS England business case approvals process, Leeds, UK.

17. Department of Health, (2016), The NHS Premises Assurance Model-2016, Leeds: UK.

18. Durán, O. (2011), “Computer-aided maintenance management systems selection based on a fuzzy AHP approach", Advances in Engineering Software, Vol. 42 No.10, pp. 821-829.

19. Fong, P.S.W. and Lee, H.F. (2009), “Acquisition, reuse and sharing of knowledge in property management firms", Facilities, Vol. 27 No. 7/8, pp. 291-314.

20. Eadie, R., Browne, M., Odeyinka, H., McKeown, C. and McNiff, S. (2013), "BIM implementation throughout the UK construction project lifecycle: An analysis", Automation in Construction, Vol. 36 December 2013, pp. 145-151.

21. Elmualim, A. and Pelumi-Johnson, A. (2009), "Application of computer-aided facilities management (CAFM) for intelligent buildings operation", Facilities, Vol. 27 No. 11/12, pp. 421-428.

22. Evchina, Y. and Lastra, J.L.M. (2018), "An approach to combining related notifications in large-scale building management systems with a rehabilitation facility case study", Automation in Construction, Vol. 87 March 2018, pp. 106-116.

23. Gnanarednam, M. and Jayasena, H.S. (2013), "Ability of BIM to satisfy CAFM information requirements", in The Second World Construction Symposium in Colombo, Sri Lanka in 2013, pp. 12-21.

24. Hareide, P.J., Bjørberg, S., Støre-Valen, M., Haddadi, A. and Lohne, J. (2016)," Strategies for optimization of value in hospital buildings", Procedia-Social and Behavioral Sciences, Vol. 226, pp. 423-430.

25. Haron, A.T. (2013), Organisational readiness to implement building information modelling: A framework for design consultants in Malysia , PhD thesis, University of Salford, UK. 
26. Irizarry, J., Gheisari, M., Williams, G. and Roper, K. (2014), “Ambient intelligence environments for accessing building information: A healthcare facility management scenario", Facilities, Vol. 32 No. 3/4, pp. 120-138.

27. Jones, K. and Sharp, M. (2007), "A new performance-based process model for built asset maintenance", Facilities, Vol 25, No 13/14, pp 525-535.

28. Kassem, M., Kelly, G., Dawood, N., Serginson, M. and Lockley, S. (2015), “BIM in facilities management applications: a case study of a large university complex", Built Environment Project and Asset Management, Vol. 5 No. 3, pp. 261-277.

29. Keller, J.W. and Keller, C. (2005), "Bringing strategic efficacy to facility management through CAFM tools", Journal of Facilities Management, Vol. 3 No.2, pp. 125-144.

30. Khosrowshahi, F. and Arayici, Y. (2012), "Roadmap for implementation of BIM in the UK construction industry", Engineering, Construction and Architectural Management, Vol. 19 No. 6, pp.610-635.

31. Lavy, S. and Fernández-Solis, J. (2010), "Complex Healthcare Facility Management and Lean Construction", HERD: Health Environments Research \& Design Journal. Volume: 3 No. 2, pp.3-6.

32. Lavy, S. and Jawadekar, S. (2014), "A Case Study of Using BIM and COBie for Facility Management", International Journal of Facility Management", Vol. 5 No. 2.

33. Lavy, S. and Saxena, N. (2015), "Quantifying the effect of using BIM and COBie for facility management on work order processing times: a case study", International Journal of Facility Management. Vol. 6 No. 1.

34. Liu, R. and Issa, R. (2012), "Automatically updating maintenance information from a BIM database", International conference in Computing in Civil Engineering in Florida, 2012, pp. 373-380.

35. Lucas, J., Bulbul, T. and Thabet, W. (2013), "An object-oriented model to support healthcare facility information management", Automation in Construction, Vol. 31 May 2013, pp. 281-291.

36. Luschi, A., Miniati, R. and ladanza, E. (2015), "A Web Based Integrated Healthcare Facility Management System", in 6th European Conference of the International Federation for Medical and Biological Engineering in Dubrovnik, Croatia, 2015, Springer, pp. 633-636.

37. Pärn, E., Edwards, D. and Sing, M. (2017), "The building information modelling trajectory in facilities management: A review", Automation in Construction, Vol. 75 March 2017, pp. 45-55.

38. Parsanezhad, P. and Dimyadi, J. (2014), "Effective facility management and operations via a BIM-based integrated information system", in CIB Facilities Management (CFM) Conference, Copenhagen, Denmark, 2014, pp.8.

39. Phiri, M. (2006), Does the physical environments affect staff and patient health outcomes?, Leeds, UK.

40. Seeley, I.H. (1976), Building Maintenance, London, UK.

41. Støre-Valen, M. and Lohne, J. (2016), "Analysis of assessment methodologies suitable for building performance", Facilities, Vol. 34 No. 13/14, pp.726-747.

42. National Health Executive, (2016), NHS high-risk maintenance backlog increases by $70 \%$. National Health Executive.com. Available at: http://www.nationalhealthexecutive.com/Health-Care-News/nhs-high-riskmaintenance-backlog-increases-by-70 (accessed 18 August 2018).

43. Redmond, K. (2016), Linking BIM, GSL and the future NHS Estates frameworks. Planning and Building Control Today. Available at: https://www.pbctoday.co.uk/news/bim-news/linking-bim-gsl-future-nhsestates-frameworks-2/22105 (accessed 18 August 2018).

44. RICS, (2012), RICS Public Sector Asset Management Guidelines. Coventry, UK.

45. Sherwin, D. (2000), "A review of overall models for maintenance management", Journal of Quality in Maintenance Engineering, Vol. 6 No. 3, pp. 138-64.

46. Shohet, I.M. and Lavy, S. (2017), "Facility maintenance and management: a health care case study", International Journal of Strategic Property Management, Vol.21 No.2, pp. 170-182.

47. Støre-Valen, M. and Lohne, J. (2016), "Analysis of assessment methodologies suitable for building performance", Facilities, Vol. 34 No.13/14, pp. 726-747.

48. Steinke, C., Webster, L. and Fontaine, M. (2010), “Evaluating Building Performance in Healthcare Facilities: An Organizational Perspective", Healthcare Environments Research and Design journal. Vol. 2 No 2, pp. 63-83.

49. Njuangang, S., Liyanage, C.L. and Akintoye, A. (2016), "Performance measurement tool (PMT) to control maintenance-associated infections", Facilities, Vol. 34 No. 13/14, pp.766-787.

50. The BIM Industry Working Group. (2011), A report for the Government Construction Client Group. The Department of Business, UK.

51. Tsang, A.H.C. (2002), "Strategic dimensions of maintenance management", Journal of Quality in maintenance engineering. Vol. 8 No. 1, pp 7-39. 
52. Ulrich, R.S. (1984), "View through a window may influence recovery from surgery", Science. Vol.224, pp.420-422.

53. Ulrich, R.S., Zimring, C.M., Zhu, X., Dubose, J.R., SEO, H.B., Choi, Y.S., Quan, X. and Joseph, A. (2008), “A review of the research literature on evidence-based healthcare design", Health Environments Research \& Design, Vol.1 No.3, pp. 61-125.

54. Volk, R., Stengel, J. and Schultmann, F. (2014), "Building Information Modeling (BIM) for existing buildings - Literature review and future needs", Automation in Construction, Vol. 38 March 2014, pp 109-127.

55. Wanigarathna, N., Jones, K., Bell, A., Desai, A., Kapogiannis, G. and Mahmudul, H. (2018), Building Information Modelling to support healthcare built-asset maintenance, UK. Available at: http://www.rics.org/uk/knowledge/research/research-reports/building-information-modelling-tosupport-healthcare-built-asset-management (accessed 18 August 2018). 